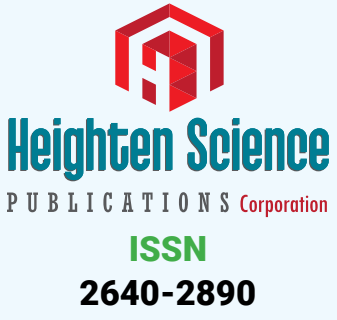

*Address for Correspondence: Ana Correia, Hospital Center of Baixo Vouga, Obstetrics and Gynecology Department, Av. Artur Ravara, 3814 Aveiro, Portugal, Tel: 00351917417525; Fax: 00351234378395; Email: anacorreia87@gmail.com

Submitted: 18 October 2018

Approved: 08 November 2018

Published: 09 November 2018

Copyright: (c) 2018 Correia A, et al. This is an open access article distributed under the Creative Commons Attribution License, which permits unrestricted use, distribution, and reproduction in any medium, provided the original work is properly cited

Keywords: Hypertension; Pregnancy-induced; Pre-eclampsia; Blood pressure monitoring; Ambulatory; Masked hypertension; White coat hypertension

Check for updates
Research Article

\section{Value of ambulatory blood pressure measure in pregnancy hypertension}

\author{
Ana Correia ${ }^{1 *}$, Sara Vidal ${ }^{2}$, Cadete Alexandra² and Fátima \\ Leitão ${ }^{1}$ \\ ${ }^{1}$ Hospital Center of Baixo Vouga, Obstetrics and Gynecology Department, Aveiro, Portugal \\ ${ }^{2}$ Health Center Grouping of Baixo Vouga, Aveiro, Portugal
}

\section{Abstract}

It is still not well known the prognostic cardiovascular value of $24 \mathrm{~h}$ ambulatory blood pressure monitoring in the pregnant woman with hypertension.

Objectives: Assess to the prognostic value of ABPM parameters in predicting maternofetal event.

Methods: Retrospective and observational study which included 166 pregnant women.

Results: The authors found that the night time DBP was the best predictor of adverse events. Non-dipper profile had worse survival at follow up until delivery compared to those with a dipper profile.

Conclusions: ABPM is a tool for pregnant with $\mathrm{HT}$ because this is the unique method available that analyses the night blood pressure.

\section{Introduction}

Pregnancy induced hypertension (PIH) complicates about 6-10\% of pregnancies and pre-existing hypertension complicates $1-5 \%$ of pregnancies [1]. The definition of hypertension in pregnancy is based on absolute blood pressure (BP) values (Systolic BP $\geq 140 \mathrm{mmHg}$ or Diastolic BP $\geq 90 \mathrm{mmHg}$ ), and distinguishes mildly (140-159/90$109 \mathrm{mmHg}$ ) or severely ( $\geq 160 / 110 \mathrm{mmHg}$ ) elevated BP [1]. It is recommended that a diagnosis require at least two determinations at least 4 hours apart, although on occasion, especially when faced with severe hypertension, the diagnosis can be confirmed within a shorter interval (even minutes) [2].

Conventional BP measures determined in the medical appointment have been routinely used for the diagnosis of hypertension (HT) and the evaluation of therapeutic efficacy. These random BP measures have, however, some limitations. For side, they provide a measure that only represents a minimal fraction of the circadian BP profile, performed under circumstances that may have a pressor effect ("white coat") and that, moreover, is obtained with a technique not exempt of potential failures [3]. The rise in blood pressure (BP) associated with clinical visit (white coat effect) may have a different mechanism and explanation and could represent a "healthy sympathic system" different from the basic mechanism of white coat hypertension (persistently raised clinic BP together with a normal BP outside the clinic) [4]. Some authors concluded that white coat hypertension, defined as high clinic BP but normal out-ofoffice BP in untreated and mixed patients, could be associated with long-term risks of cardiovascular disease and total mortality compared with normotension [5].

The Ambulatory Blood Pressure Monitoring (ABPM) is the method of blood pressure measurement that allows recording blood pressure measures in 24 hours and his 
circadian rhythm and evaluating various parameters such as mean BP, pressure loads, areas under the curve, variations between daytime and night time, pulse pressure variability [6]. Twenty four-hour ambulatory monitoring is considered as the best predictor of cardiovascular risk in the individual patient and is the only technique that can describe the circadian rhythm of blood pressure accurately, which may be even more important when considering pregnant women [7].

In the 60's decade (i.e. five decades ago), Kain et al., demonstrated the benefits of ABPM, and the attractive possibility of measuring blood pressure during patients' daily activities. According to a search performed on MEDLINE database on May 11, 2015, since 2001, more than 2000 articles have been published every five years, showing the importance of this revolutionary method in the establishment of diagnosis and prognosis of patients with altered blood pressure, and in the assessment of the antihypertensive therapy. The first study, published in 1962, was crucial for demonstrating the assessment of 24 -hour blood pressure without an observer, using a semi-automatic method [6].

ABPM is performed with the patient wearing a portable BP measuring device, usually on the non-dominant arm, for a 24-25 h period, so that it gives information on BP during daily activities and at night during sleep. The patient is asked to provide information in a diary on symptoms and events that may influence BP, in addition to the times of drug ingestion, meals and going to and rising from bed. In clinical practice, measurements are often made at 15 min intervals during the day and every $30 \mathrm{~min}$ overnight. The measurements are downloaded to a computer and a range of analyses can be performed. At least $70 \%$ of BPs during daytime and night-time periods should be satisfactory, or else the monitoring should be repeated [8].

For pregnancy related complications, hypertension is the most common, and can occur as gestational hypertension, preeclampsia, chronic hypertension, or preeclampsia superimposed on chronic hypertension. Women who develop these complications during pregnancy have a greater chance to develop cardiovascular disease later in life [9]. According to the WHO, PIH is one of the main causes of maternal, fetal and neonatal mortality and morbidity. It is the most common cause of maternal death in Europe. Women with PIH are at a greater risk of abruption placentae, cerebrovascular events, organ failure and disseminated intravascular coagulation. Fetuses of these mothers are at greater risk of intrauterine growth retardation, prematurity and intrauterine death [10].

Hypertension in pregnancy, as diagnosed by ABPM, is superior to the office measurement of BP in predicting outcomes [1] and seems to have a role in predicting deterioration from gestational hypertension to adverse events in pregnancy [10].

The main objective of this study is evaluate the relationship between the results of ambulatory blood pressure parameters and its relationships in the occurrence of adverse events in pregnancy.

\section{Methods}

Retrospective and observational study which included 166 pregnant women designed from the Obstetrics appointment to the Cardiology/Hypertension appointment, having done the ABPM, between January 2007 and June 2016. The pregnant women included were those who ABPM revealed values compatible with hypertension. Pregnant women who did not meet criteria in ABPM of hypertension were excluded. The following data were evaluated: age, personal history, obstetrics, family, body mass index, weight gain in pregnancy, values of blood pressure in the appointment, values recorded in ABPM, delivery and new born, pregnancy and postpartum events, follow-up of woman and child. The defined events were: mother, fetal or neonatal dead, preeclampsia, eclampsia, gestational diabetes, prematurity and fetal growth restriction. 
In addition to the values obtained through the ABPM, we calculated the fall (or dip, \%) of mean BP from awake to sleep BP: (mean awake BP-mean sleep BP)/mean awake $\mathrm{BP} \times 100 \%$. If the sleep systolic BP (SBP) was $<10 \%$ lower than the awake SBP, the subject was categorized as a nondipper.

Data were analysed using descriptive and inferential statistics with the Statistical Package for the Social Science (SPSS $®$ ) for Windows (version 21.0). For the inferential analysis we used the cross-tables of variables with the application of the chi-square test. When a significant association between the variables was detected by the chisquare test. To compare the results of ABPM according to the event occurrence, we used the t-student parametric test for independent samples. The significance level of $5 \%$ was used to all the statistical studies. The study was approved by the ethics committee of the hospital.

\section{Results}

The sample is composed by 166 pregnant women, who performed ambulatory blood pressure monitoring (ABPM) following the follow-up in the consultation of Pregnancy and Hypertension, which revealed criteria of hypertension (HT). In the sample studied the mean age was 31.7 years with a standard deviation of 5.58 years (minimum of 19 years and maximum of 48 years). Regarding the classification of type of hypertension, 93 pregnant women (56\%) had chronic HT, 73 gestaional HT (44\%), and 8 had a previous history of unmedicated HT (Table 1).

From the obtained data, the event in pregnancy (Table 2) happened in about half of the group studied - 49.4\% (82). In the sample, $60.8 \%$ (101) of the women had previous HT and of these $50.5 \%$ (51) had an event record. Previous gestational HT had occurred in $24.1 \%$ (40) of the women and of these 23 had an event occurrence. Previous preeclampsia occurred in $13.9 \%$ (23) of the women and of these $65.2 \%$ (15) had an event occurrence. Obesity was observed in $50 \%$ (83) of the women and of these $51.8 \%$ (43) had an event occurrence. The family history of cardiovascular events occurred in $27.1 \%$ (45) of the women, and 20 of these women had an event record.

\begin{tabular}{|c|c|c|c|}
\hline & $\begin{array}{c}\text { Gestacional HT } \\
n=73\end{array}$ & $\begin{array}{c}\text { Chronic HT } \\
n=93\end{array}$ & $p$ value \\
\hline Age & 30,1 & 32,9 & 0,001 \\
\hline Body mass index & 31,6 & 30,7 & 0,407 \\
\hline Weight gain in pregnancy & 12,8 & 10,6 & 0,043 \\
\hline Number of cardiovascular risk factors & 1,6 & 2,2 & 0,009 \\
\hline Systolic blood pressure at appointment & 137,5 & 134,1 & 0,095 \\
\hline $\begin{array}{l}\text { Diastolic blood pressure at } \\
\text { appointment }\end{array}$ & 87,6 & 86,2 & 0,362 \\
\hline Gestacional age at ABPM & 27 & 22 & $<0,001$ \\
\hline Gestacional age at birth & 37,8 & 37,6 & 0,569 \\
\hline New born weight & 2968 & 2952 & 0,894 \\
\hline
\end{tabular}

Table 2: Characterization of the occurrence of the event and Chi-square test results.

\begin{tabular}{|c|c|c|c|c|}
\hline \multirow[b]{2}{*}{ Personal History Data } & & \multicolumn{3}{|l|}{ Event } \\
\hline & & $\begin{array}{c}\text { No } \\
n=84\end{array}$ & $\begin{array}{c}\text { Yes } \\
n=82\end{array}$ & $\begin{array}{c}\text { Chi-square test ( } p \\
\text { value) }\end{array}$ \\
\hline \multirow{2}{*}{ Previous HT } & No & 34 & 31 & \multirow{2}{*}{$0,124(0,724)$} \\
\hline & Yes & 50 & 51 & \\
\hline \multirow{2}{*}{ Previous gestacional HT } & No & 67 & 59 & \multirow{2}{*}{$1,384(0,239)$} \\
\hline & Yes & 17 & 23 & \\
\hline \multirow{2}{*}{ Previous pre-eclâmpsia } & No & 76 & 67 & \multirow{2}{*}{$2,673(0,102)$} \\
\hline & Yes & 8 & 15 & \\
\hline \multirow{2}{*}{ Obesity } & No & 44 & 39 & \multirow{2}{*}{$0,386(0,535)$} \\
\hline & Yes & 40 & 43 & \\
\hline \multirow{2}{*}{$\begin{array}{l}\text { Family history of cardiovascular } \\
\text { disease }\end{array}$} & No & 59 & 62 & \multirow{2}{*}{$0,606(0,436)$} \\
\hline & Yes & 25 & 20 & \\
\hline
\end{tabular}


By applying the chi-square independence test, it was found that, at a significance level of $5 \%$, the occurrence of the event was statistically independent of previous HT, previous gestational HT, previous preeclampsia, obesity and family history of cardiovascular disease. Thus, no differences were found in the variables described regarding the occurrence of an event during pregnancy.

In the analysis of the continuous variables (Table 3 ), by applying the parametric test $t$, it was found that, at a significance level of $5 \%$, there are statistically significant differences for the occurrence of adverse event in pregnancy according to age, weight gain in pregnancy, systolic blood pressure (SBP) value in the appointment, diastolic blood pressure (DBP) value in the appointment, new born birth weight and gestational age at the delivery.

Table 4 presents the comparison between the different blood pressure results revealed in ABPM in function of the occurrence of adverse event in pregnancy. It was found that the results of 24h-SBP and 24h-DBP were, on average, higher in women who had an adverse event record. The differences observed were statistically significant, with a significance level of $5 \%$ (parametric test $t$ ). It can be affirmed that women with adverse event in pregnancy had significantly higher mean values of 24h-SBP and 24h-DBP than women without event registration. The analysis of results found that women with event registration had higher mean values in the SBP-day and DBP-day measures, the differences being statistically significant only for the DBP-day. Regarding the measurements of nocturnal blood pressure, it was observed that women with adverse event occurrence recorded had higher mean values on SBP by night and DBP by night than women without

Table 3: Comparison of age, BMI, weight gain in pregnancy, SBP and DBP values in the appointment, new born weight at birth and gestational age at delivery depending on the occurrence of the event.

\begin{tabular}{|c|c|c|c|c|c|}
\hline Parameter & Event & $\mathbf{n}$ & Average & Standard deviation & $p$ value \\
\hline \multirow{2}{*}{ Age } & No & 84 & 30,9 & 5,1 & \multirow{2}{*}{0,046} \\
\hline & Yes & 82 & 32,6 & 5,9 & \\
\hline \multirow{2}{*}{ BMI } & No & 84 & 30,7 & 6,2 & \multirow{2}{*}{0,48} \\
\hline & Yes & 82 & 31,5 & 7,8 & \\
\hline \multirow{2}{*}{$\begin{array}{l}\text { Weight gain in } \\
\text { pregnancy }\end{array}$} & No & 84 & 12,8 & 7,0 & \multirow{2}{*}{0,024} \\
\hline & Yes & 82 & 10,3 & 6,8 & \\
\hline \multirow{2}{*}{$\begin{array}{c}\text { SBP at } \\
\text { appointment }\end{array}$} & No & 84 & 132,1 & 12,4 & \multirow{2}{*}{$<0,000$} \\
\hline & Yes & 82 & 139,3 & 12,3 & \\
\hline \multirow{2}{*}{$\begin{array}{c}\text { DBP at } \\
\text { appointment }\end{array}$} & No & 84 & 84,4 & 9,6 & \multirow{2}{*}{$<0,001$} \\
\hline & Yes & 82 & 89,2 & 8,6 & \\
\hline \multirow{2}{*}{$\begin{array}{l}\text { New born weight } \\
\text { at birth }\end{array}$} & No & 84 & 3192 & 657 & \multirow{2}{*}{$<0,000$} \\
\hline & Yes & 82 & 2719 & 805 & \\
\hline \multirow{2}{*}{$\begin{array}{c}\text { Gestacional age } \\
\text { at birth }\end{array}$} & No & 84 & 38 & 1 & \multirow{2}{*}{$<0,000$} \\
\hline & Yes & 82 & 36 & 2 & \\
\hline
\end{tabular}

Table 4: Comparison of the results of ABPM parameters in function of the adverse event occurrence.

\begin{tabular}{|c|c|c|c|c|c|}
\hline ABPM parameter & Event & $\mathbf{n}$ & Average & Standart desviation & p value \\
\hline \multirow{2}{*}{ SBP 24h } & No & 83 & 120,1 & 12,3 & \multirow{2}{*}{0,021} \\
\hline & Yes & 82 & 124,6 & 12,4 & \\
\hline \multirow{2}{*}{ DBP 24h } & No & 83 & 73,5 & 8,3 & \multirow{2}{*}{0,004} \\
\hline & Yes & 82 & 77,7 & 9,6 & \\
\hline \multirow{2}{*}{ SBP day } & No & 83 & 125,9 & 12,3 & \multirow{2}{*}{0,069} \\
\hline & Yes & 82 & 129,4 & 11,9 & \\
\hline \multirow{2}{*}{ DBP day } & No & 83 & 78,9 & 8,7 & \multirow{2}{*}{0,025} \\
\hline & Yes & 82 & 82,1 & 9,6 & \\
\hline \multirow{2}{*}{ SBP night } & No & 83 & 110,0 & 13,9 & \multirow{2}{*}{0,012} \\
\hline & Yes & 82 & 115,4 & 13,3 & \\
\hline \multirow{2}{*}{ DBP night } & No & 83 & 64,5 & 8,9 & \multirow{2}{*}{0,001} \\
\hline & Yes & 82 & 69,5 & 10,5 & \\
\hline \multirow{2}{*}{$\begin{array}{l}\text { Nocturnal dipping } \\
\text { of SBP }\end{array}$} & No & 83 & 15,0 & 7,2 & \multirow{2}{*}{0,08} \\
\hline & Yes & 82 & 12,7 & 9,1 & \\
\hline \multirow{2}{*}{$\begin{array}{c}\text { Nocturnal dipping } \\
\text { of DBP }\end{array}$} & No & 83 & 23,1 & 9,2 & \multirow{2}{*}{0,011} \\
\hline & Yes & 82 & 19,0 & 10,8 & \\
\hline
\end{tabular}


adverse event. These observed differences in SBP-night and DBP-night were statistically significant, with a significance level of $5 \%$. Analysing the nocturnal descent of the arterial pressure (dipper profile), it was observed that the women with adverse event occurrence recorded lower dipping values of SBP and DBP at night, lower compared to women without events. With a significance level of $5 \%$ the differences were statistically significant for the nocturnal descent of the DBP.

\section{Discussion}

The main goal in our study was demonstrate the importance of ABPM in the diagnostic approach and treatment of hypertension in pregnancy as a way to access some predictors of maternal-fetal adverse outcomes. Both systolic and diastolic blood pressure is not constant over twenty-four-hour period. It shows characteristic circadian pattern in all individuals, including non-pregnant and pregnant women in response to internal clock and mental and physical activity [11]. As others studies, the ABPM has been demonstrated to improve the diagnostic approach and the risk prediction in a general hypertensive population, and evidence is available also to support their usefulness in the management of hypertensive disorders in pregnancy [11-13]. ABPM has been specifically recommended for the identification of white-coat hypertension and the presence of masked hypertension because it allows evaluate the elevation in daytime BP, night-time BP or both [14]. Although previous studies did already suggest that nocturnal BP may be relevant in pregnancy [13], in our study we showed that the absence of physiological decrease in nocturnal blood pressure (non-dipper profile), especially diastolic values, are related to the appearance of adverse maternal-fetal events, presenting superior and independent value in relation to the physiological decrease of blood pressure values (dipper profile). On our study nocturnal hypertension has a strong power as predictor for the development of adverse events in pregnancy when is adjusted for other potential confounders, being the nocturnal diastolic values the best predictors remaining statistically significant after adjustment for the other ABPM values. In the young population, the HT is mostly defined at the expense of the diastolic values in comparison to the systolic ones. It is possible to think that the peripheral resistances are one of the important components to be taken into account in these cases [15]. It is known that in the general population, nocturnal hypertension is best associated with target organ damage and cardiovascular events and it was already described that these findings appear particularly relevant considering that nondipping circadian BP profiles are common in preeclampsia [13]. The access of this values is only possible with a method of blood pressure monitoring like ABPM; however, the only problem is when sleep has no quality either of which could selectively increase nocturnal BP while, at the same time, affecting outcome [12].

\section{Conclusion}

Blood pressure monitoring by ambulatory method is very precise. Standardized twenty-four-hour blood pressure monitoring in pregnant women allows quantitative and qualitative evaluation of hypertensive status and is very important for regularization of timing and dosing of antihypertensive medications. ABPM could be a recommended approach for hypertensive diseases during pregnancy as diagnostic and treatment orientation method namely in conditions as white-coat effect, masked hypertension, nocturnal hypertension and nondipping profile. However, the available studies do not provide specific indications for its use in these conditions and do not clarify which of them should be preferred and in what situation. With our study we were able to deepen the quality of diagnosis and prognosis improving clinical management in a difficult but clinically highly relevant field such as hypertensive disorders in pregnancy, emphasizing the importance of the absence of physiological decrease of nocturnal blood pressure values, namely the diastolic values, as predictors of adverse events in these 
hypertension complicated pregnancies. Future prospects: if ABPM became a tool in the consultation of HT in the pregnant woman it would be possible to reduce the false HT and decrease cardiovascular events, on the one hand, the current evidence obtained, the study of a more generalized sample of the night period and until the stiffness would give other answers. On the one hand, these same tools could allow us to evaluate how best to reduce the variability and its consequences.

\section{References}

1. European Society of Gynecology (ESG); Association for European Paediatric Cardiology (AEPC): German Society for Gender Medicine (DGesGM), Regitz-Zagrosek V, Blomstrom Lundqvist C, et al. ESC Guidelines on the management of cardiovascular diseases during pregnancy: the Task Force on the Management of Cardiovascular Diseases during Pregnancy of the European Society of Cardiology (ESC). Eur Heart J 2011; 32: 3147-3197. Ref.: https://goo.gl/dQjGjh

2. American College of Obstetricians and Gynecologists, Task Force on Hypertension in Pregnancy. Hypertension in pregnancy. Obstet Gynecol 2013; 1022:1122. Ref.: https://goo.gl/48PhK2

3. Hermida RC, Ayala DE, Calvo C. Valor de la monitorización ambulatoria de la presión arterial en la predicción de daño en órganos diana e incidencia de eventos cardiovasculares. Nefrología 2002; 22: Suppl 3. 59-67. Ref.: https://goo.gl/zH35BK

4. Verdecchia P1, Schillaci G, Borgioni C, Ciucci A, Zampi Im et al, White coat hypertension and white coat effect. Similarities and differences. Am J Hypertens. 1995; 8: 790-798. Ref.: https://goo.gl/gTaSB2

5. Huang Y, Huang W, Mai W, Cai X, An D, et al. White-coat hypertension is a risk factor for cardiovascular diseases and total mortality. J Hypertens. 2017; 35: 677-688. Ref.: https://goo.gl/q5yXJd

6. Ogedegbe G, Pickering T. Principles and techniques of blood pressure measurement. Cardiol Clin. 2010; 28: 571-586. Ref.: https://goo.gl/2Jm4PQ

7. Nobre F, Mion Junior D. Ambulatory Blood Pressure Monitoring: Five Decades of More Light and Less Shadows. Arq Bras Cardiol. 2016; 106: 528-537. Ref.: https://goo.gl/nhL3gF

8. The Task Force for the management of arterial hypertension of the European Society of Hypertension (ESH) and of the European Society of Cardiology (ESC). 2013 ESH/ESC Guidelines for the management of arterial hypertension. European Heart Journal 2013; 34: 2159-2219. Ref.: https://goo.gl/ZePVBt

9. Gongora MC, Wenger NK. Cardiovascular Complications of Pregnancy. Int J Mol Sci. 2015; 9-16: 23905-23928. Ref.: https://goo.gl/sjJqDn

10. Kintiraki E, Papakatsika S, Kotronis G, Goulis DG, Kotsis V. Pregnancy-Induced hypertension. Hormones (Athens) 2015; 14: 211-223. Ref.: https://goo.gl/Pqx48x

11. Gupta HP, Singh RK, Singh U, Mehrotra S, Verma NS, et al. Circadian pattern of blood pressure in normal pregnancy and preeclampsia. J Obstet Gynaecol India 2011; 61: 413-417. Ref.: https://goo.gl/bPAMiQ

12. Bilo G, Parati G. Ambulatory blood pressure monitoring: a mandatory approach in high-risk pregnancy? J Hypertens 2016; 34: 2140-2142. Ref.: https://goo.gl/EbvPV3

13. Salazar MR, Espeche WG, Leiva Sisnieguez BC, Balbín E, Leiva Sisnieguez CE, et al. Significance of masked and nocturnal hypertension in normotensive women coursing a high-risk pregnancy. $J$ Hypertens 2016; 34: 2248-2252. Ref.: https://goo.gl/6pUxFy

14. Brown MA. Is there a role for ambulatory blood pressure monitoring in pregnancy? Clin Exp Pharmacol Physiol 2014; 41: 16-21. Ref.: https://goo.gl/UXchdu

15. Mesquita-Bastos J, Bertoquini S, Polónia J. Cardiovascular prognostic value of ambulatory blood pressure monitoring in a Portuguese hypertensive population followed up for 8.2 years. Blood Press Monit 2010; 15: 240-246. Ref.: https://goo.gl/hgdxGF 